\title{
Health locus of control and depressive symptoms among adolescents in Alexandria, Egypt
}

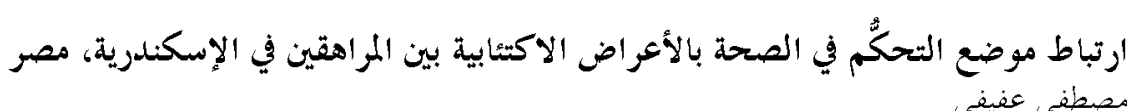

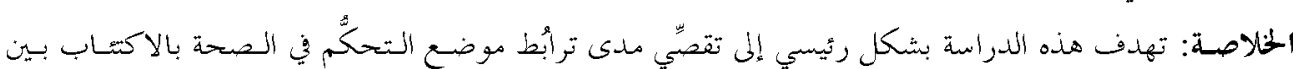

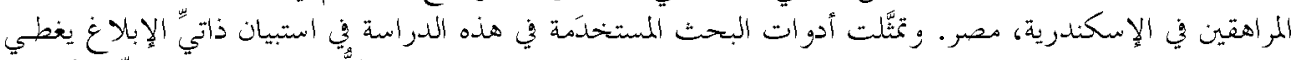

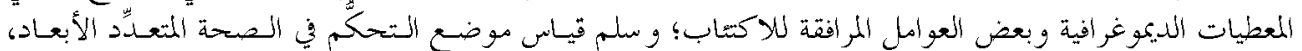

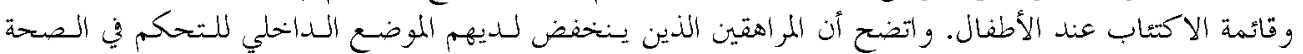

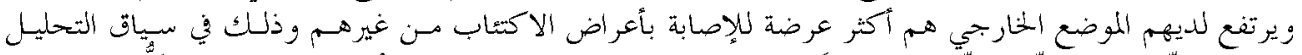

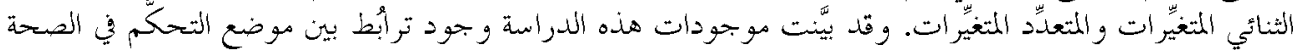
وبين الاكتياب لندى المراهين.

ABSTRACT The aim of this work was to investigate the association of health locus of control with depression among adolescents in Alexandria, Egypt. The tools used were a self-report questionnaire covering demographic data and some factors associated with depression, the Multidimensional Health Locus of Control scale and the Child Depression Inventory. Adolescents with low internal health locus of control and high chance external health locus of control were more likely to have depressive symptoms than others in bivariate and multivariate analysis. The study findings demonstrated an association between health locus of control and adolescent depression.

Lieu de contrôle de la santé et symptômes dépressifs chez les adolescents d'Alexandrie en Égypte

RÉSUMÉ Cette étude avait pour objectif d'analyser l'association lieu de contrôle de la santé et dépression chez des adolescents d'Alexandrie en Égypte. Les instruments utilisés à cette fin étaient un auto-questionnaire couvrant les données démographiques et certains facteurs associés à la dépression, l'échelle MHLC (pour Multidimensional Health Locus of Control - échelle du lieu de contrôle multidimensionnel de la santé) et l'échelle CDI (pour Child Depression Inventory - échelle de dépression de l'enfant et de l'adolescent). Les analyses bivariées et multivariées montrent que les adolescents obtenant un faible score de contrôle interne et un score élevé pour le contrôle externe de type " chance " sont plus susceptibles que les autres de présenter des symptômes dépressifs. Les résultats de l'étude démontrent l'existence d'une association entre le lieu de contrôle de la santé et la dépression de l'adolescent.

${ }^{1}$ Department of Research and Studies, Ministry of Health, Oman (Correspondence to M. Afifi: afifidr@yahoo. co.uk).

Received: 04/09/05; accepted 15/11/05 


\section{Introduction}

Adolescence is a formative period during which many life patterns are learned and established [1]. Understanding the health belief of adolescents is crucial for effective health education. Health beliefs that influence lifestyle behaviour are complex, but are usually acquired during childhood and adolescence [2]. Information preference is positively associated with decisional preference among individuals who believe their health is less dependent on influential others, i.e. those who have internal rather than external health consciousness, or simply those not having external health locus of control (HLC). Influential others HLC, as well as chance HLC, is a type of external HLC. Individuals may use medical information for different purposes according to the type of health-related attribution beliefs [3].

Health locus of control is one of the most widely measured parameters of health belief for the planning of health education programmes [4]. The Multidimensional Health Locus of Control (MHLC) scale contains 3 subscales: internal HLC (IHLC), chance HLC (CHLC), and powerful others HLC (PHLC) [5]. Each subscale measures individual tendency to believe that health outcomes are mainly a result of one's own behaviour (IHLC), to chance (CHLC), or to powerful others such as medical professionals or family (PHLC); CHLC and PHLC are classified as "external" belief and IHLC as "internal" belief [5].

In rapidly changing societies such as are found in the Eastern Mediterranean Region, where a great shift in the age distribution of the population occurred in 1980s and 1990s, it would be inappropriate to follow the same priorities as earlier. Adolescent psychiatric disorders have become more frequent and occur at an earlier age during their life span [6]. Despite this, child and adolescent psychiatry is still not gaining much interest $[7,8]$ although behavioural problems among children and adolescents are on the increase in some countries of this Region as well as other developing countries [7].

Early-onset depression often persists, recurs and continues into adulthood, indicating that depression in youth may also predict more severe illness in adult life. Moreover, depression in children and adolescents is associated with increased risk of suicidal behaviours [9].

Correlates of depression differ according to country and culture. Depression prevention programmes have to take such differences into consideration [10]. Research on the association between health locus of control and depression in chronic illness has produced contradictory findings, perhaps because of a failure to consider contextual variables [11].

The aim of this study was to investigate the health beliefs of adolescents in Alexandria, Egypt, using the MHLC scale and to examine the association of IHLC and CHLC with depressive symptoms in adolescents.

\section{Methods}

\section{Study subjects and tools}

The study is based on a data set from studies carried out in 1996 [10,12]. From each of the 6 districts of Alexandria, 2 secondary schools, 1 boys' school and 1 girls' school, were selected by systematic stratified random sampling. A whole class (around 45 students per class) from each grade (1st, 2nd, 3rd secondary) was randomly selected, i.e. 36 classes altogether. Written consent was obtained from the Ministry of Education before commencing the study. None of the students in the selected classes refused to participate. The total number of participants was 1577. 
A self-report questionnaire was designed by the researcher to be completed by the students. It covered demographic and personal data as well as questions on factors associated with depression. History of physical abuse was determined through asking the participants whether they had ever been subjected to physical abuse (that they considered humiliating and/or painful, i.e. positive response depended on the perception of the child) by one of their parents [13].

Current cigarette smoking was enquired about through raising a screening question, i.e. whether participants were smoking at the time or not. The adolescent-parental relationship was classified as good, acceptable or bad arbitrarily according to the respondent's point of view. Family history of mental illness was investigated by asking participants whether any of their close relatives (immediate family, first cousins, uncles, aunts) had a history of mental illness.

To obtain a history of emotional disturbance, students were asked if they had had any emotional or psychological problems that made them consult a doctor in the year prior to the study.

The Arab Social Class Scale was applied to participants' responses [14]. This uses the degree of parents' education, parents' occupation and crowding index (number of family members divided by number of closed rooms in the accommodation). The scale scores ranged from $0-25$ with 3 categories: $\geq 20$ high social class, 13-19 middle class $<13$ low social class.

Pre-testing of the questionnaire was conducted on 100 students of both sexes from a secondary school in Alexandria before running the study.

Further tools were used to assess adolescent HLC and depression. The students were asked about their HLC beliefs: IHLC denotes that the student believes that his/her health is the outcome of his/her deeds, while CHLC denotes that he/she believes that chance plays a great role in being or staying healthy.

The multidimensional health locus of control form A, developed by Wallston and Wallston in 1978, contains 18 questions classified into 3 subscales: internal, chance and powerful others [5]. The first 2 subscales (IHLC and CHLC) were translated into Arabic by the author, guided by the opinion of a professional English teacher. Reliability was tested by calculating Cronbach's alpha to assess internal consistency.

The third subscale, PHLC, was not included in the study because the questionnaire was enough for the respondents. The author considered the CHLC adequate for testing for external locus of control in adolescents. This did not affect the validity of the tool as Cronbach's alpha is calculated for each subscale separately. Both IHLC and CHLC subscales showed acceptable level of internal consistency, i.e. $>0.40$ ( 0.51 and 0.48 respectively). Each subscale contains 6 questions; for each question, participants choose 1 of 6 answers ranging from strongly agree $=6$ to strongly disagree $=1$. Accordingly, the total score for each subscale ranges from 6 to 36 [5]. The mean score for each subscale, not the individual items, was used in the statistical analysis of the data.

The Arabic version of the 27-item Children's Depression Inventory (CDI) [15], which covers an array of overt symptoms of child and adolescent depression such as sadness, suicidal ideation, sleep and appetite disturbance, was also used. Each item assesses 1 symptom by presenting 3 choices ranging from 0 to 2 in the direction of increasing psychopathology; total score ranges from 0 to 54 . Those who scored $\geq 20$ were considered as having at least mild 
depressive symptoms. The CDI test-retest reliability was 0.9 . It took around $40-50$ minutes for each student to complete the questionnaire and the other tools (around a class session).

\section{Ethical issues}

To preserve confidentiality, no direct or indirect identification of respondents was used. The school principals as well as the participants gave their verbal consent to participate in the study.

\section{Data processing and analysis}

Data entry was done using Epi-Info, version 2.1 and analysis was done with SPSS, version 9.0. The association between HLC score and demographic and other variables was examined. Finally the association between HLC and having depressive symptoms, adjusting for other confounders, was examined.

\section{Results}

The mean age of the sample was 15.8 [standard deviation (SD) 1.3; range 14-19] years. Almost half the participants $(49.8 \%)$ were males. Mean birth order was 2.5 (SD 1.6). About $15 \%$ had a history of dropping a class in their academic history and around 20\% had been subjected to physical abuse during childhood. While only $6 \%$ had a family history of mental illness, $12.0 \%$ had personal history of mental illness and $17.0 \%$ had at least mild depressive symptoms, i.e. CDI score $\geq 20$, the cut-off score.

The mean IHLC score (SD) was 25.15 (4.76) whereas the mean CHLC score (SD) was 22.67 (5.30) (Table 1). Mean CDI score (SD) was 13.21 (6.17).

Mean IHLC scores varied significantly with sex, history of dropping classes and having depressive symptoms. Mean CHLC scores differed significantly according to sex, history of abuse in childhood, adolescent-parent relationship, family history of mental illness. personal history of mental illness and having depressive symptoms. Those abused during childhood were more likely to have higher mean CHLC scores than those who had not been subjected to physical abuse. Boys had significantly higher IHLC and lower CHLC than girls. Those classed as having depressive symptoms had significantly lower mean IHLC score and higher mean CHLC score than those who did not have depressive symptoms (Table 1). Birth order was not associated with either IHLC or CHLC before or after adjustment for sex. However IHLC and CHLC scores showed significant positive correlation adjusted for sex (correlation coefficient $r=0.22, P<0.001$ ) denoting that adolescents with higher scores for IHLC were more likely to have also higher scores for CHLC (data not shown).

Variables significantly associated with IHLC and/or CHLC in bivariate analysis were re-examined in multivariate analysis. The association of IHLC and CHLC with adolescent depression, adjusted for age, sex, social class, history of physical abuse during childhood, history of dropping class, having a hobby, current smoking, parental relations, family history of mental problems, personal history of mental problems and birth order were examined in a logistic regression model. Higher IHLC scores were significantly protective against adolescent depression adjusted for the aforementioned variables (Table 2). In contrast, those with higher CHLC were more likely to have depressive symptoms than those with lower scores. Girls were 2.6 times more likely to have depressive symptoms than boys. Those with a history of abuse in childhood, current smokers, older children and those with higher birth order were more likely to have depressive symptoms than others. 


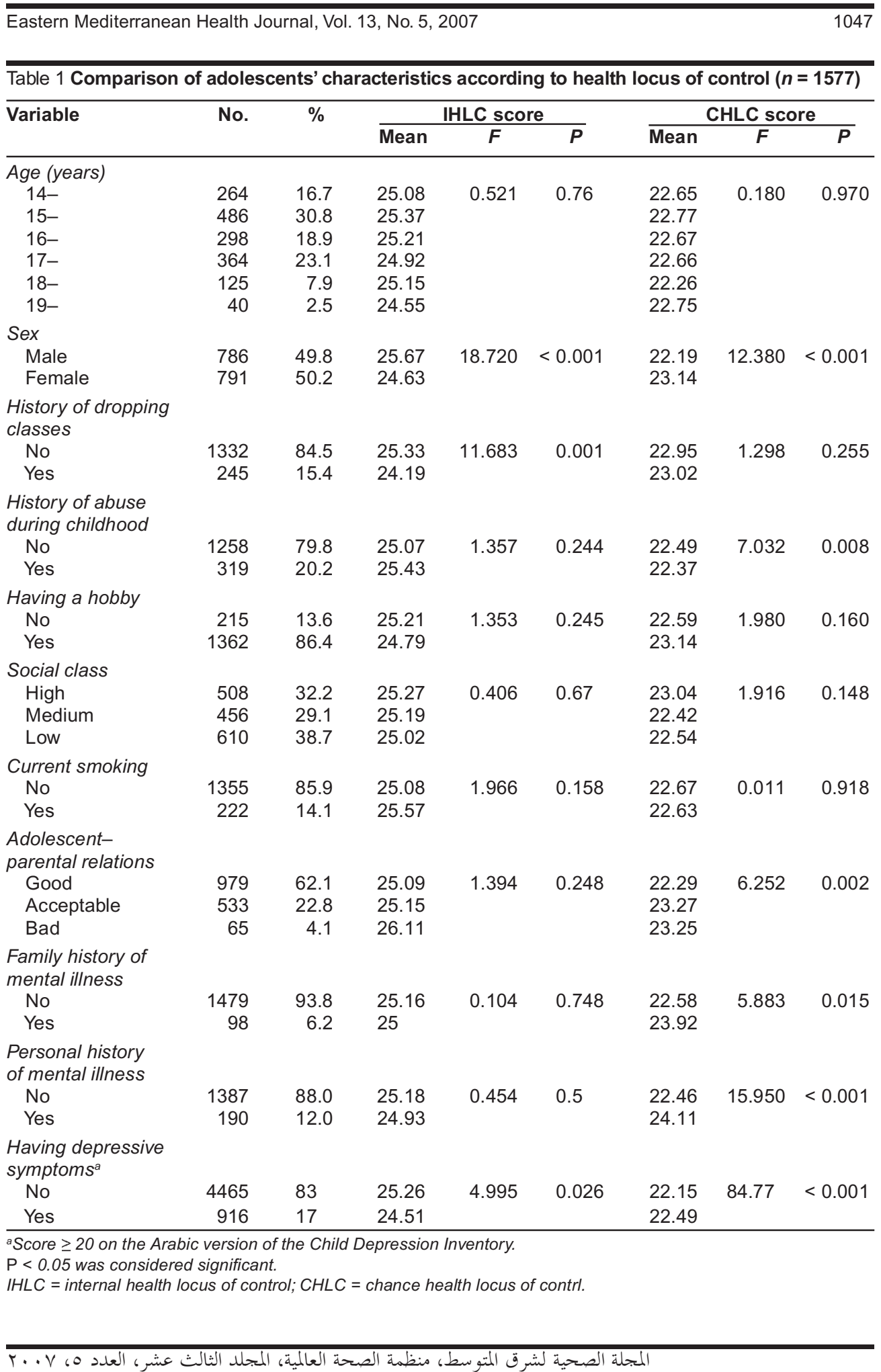




\section{Discussion}

Adolescent mental health in the Eastern Mediterranean Region generally, and in Egypt specifically, is still not a prime focus of policymakers, researchers and health providers. The findings of this study add to the existing knowledge about Egyptian adolescents in Alexandria.

The data show that CHLC scores were higher for girls than boys and vice versa for IHLC in the current study. This is similar to the findings of a previous study on an adult population [4]. Adolescents with past history of physical abuse during childhood were more likely to score higher external chance locus of control in the current study. Internal locus of control is considered one of the common protective factors for child abuse. Moreover, having parents with external locus of control is a familial risk factor for child abuse [16]. The association be-

\begin{tabular}{|c|c|c|c|}
\hline Variable & OR & $95 \% \mathrm{Cl}$ & $P$ \\
\hline \multicolumn{4}{|c|}{$\begin{array}{l}\text { History of abuse } \\
\text { during childhood }\end{array}$} \\
\hline No & 1 & & \\
\hline Yes & 3.28 & $2.38-4.54$ & $<0.001$ \\
\hline \multicolumn{4}{|l|}{ Sex } \\
\hline Male & 1 & & \\
\hline Female & 2.59 & $1.83-3.67$ & $<0.001$ \\
\hline Age & 1.15 & $1.02-1.29$ & 0.024 \\
\hline CHLC & 1.15 & $1.11-1.19$ & $<0.001$ \\
\hline IHLC & 0.94 & $0.91-0.97$ & 0.003 \\
\hline \multicolumn{4}{|c|}{ Current smoking } \\
\hline No & 1 & & \\
\hline Yes & 2.24 & $1.42-3.51$ & 0.005 \\
\hline \multicolumn{4}{|c|}{ Having a hobby } \\
\hline No & 1 & & \\
\hline Yes & 1.51 & $1.02-2.23$ & 0.041 \\
\hline Birth order & 1.1 & $1.01-1.21$ & 0.034 \\
\hline
\end{tabular}

tween CHLC and being subjected to physical abuse could be related to the poor future orientation of the children with external or chance locus of control, who are not as committed or assertive as those with internal locus of control and accordingly prone to mistakes, which in turn predisposes them to being punished.

The data of the current study did not prove an association of health locus of control with adolescents' social class. The social gradient in relation to sense of control has previously been reported, with higher levels of fatalism and lower beliefs in personal control, in lower socioeconomic status groups [17]. Data from some other studies showed no difference between social classes regarding belief in internal locus of control, only in chance locus of control [4]. This supports the argument that control beliefs are multidimensional [18], and that individuals can simultaneously hold strong beliefs in the relevance of their own actions and in the play of chance, which was demonstrated in the current study by the significant positive correlation between IHLC and CHLC.

The association between HLC and depression was significant for each of the dimensions measured, i.e. IHLC and CHLC. Adolescents who were oriented toward CHLC were more likely to report depressive symptoms in the current study. The association of depressive symptoms with locus of control was shown in previous studies. High external locus score significantly increased the risk for behavioural problems in general [19]. Takakura and Sakihara explained that external locus of control produced feelings of hopelessness characterizing depressive phenomena because the people experiencing them tended to perceive outcomes as beyond their control. This supports the learned helplessness model in which individuals become helpless and depressed when they 
perceive events as uncontrollable [20]. In a Norwegian study, external locus of control in combination with poor social support increased the risk of developing mental disorder when exposed to negative life events [21]. External locus of control, in terms of a supposedly personality-related feeling of powerlessness, predicted mortality. Depression has also been associated with strong beliefs in the influence of chance over health [22]. Sosklone et al. also found that higher scores of depressive symptoms were significantly associated with lower scores of internal and higher scores of external health locus of control [23].

Lower sense of self control over illness not only predicts mental illness but is also associated with adherence to medication. The relationship between social support and antidepressant medication adherence is moderated by beliefs about control over illness. Increasing subjective and instrumental social support and non-family interaction were associated with greater adherence among patients with high internal locus of control but not among patients low in internal locus of control [24]. This could be explained by the "regression" experienced by those with high external locus of control in the sense of relinquishing some of their control to their formal or informal care givers. Therefore, efforts to endow the patient with optimal degree of control may help him or her to become a better partner in medical decisions [23].

The strong link between adolescent and adult depression has been demonstrated previously, irrespective of co-morbidity [25]. Accordingly, it is worth discussing the other variables associated with adolescent depression in this study, which could help in formulating a protective health education programme for adolescent and adult depression. The current data show that female sex, child abuse, smoking and higher birth order were significantly associated with depression. The sex difference has been demonstrated in many previous studies, with predominance among girls, and could be explained by higher levels of self competence among boys, indicated in the Ohannessian et al. study [26]. Smoking was associated with depression in the current study. There is a strong positive correlation between cigarette consumption and depression [27]. Depressed adolescents are more likely to begin smoking, to smoke more and to continue smoking than young adults are. Smokers with mild or major depression find it hard to quit smoking [28-30]. The association of CHLC with childhood abuse and poor parental relationship and the link between childhood abuse and CHLC with depression in the current data is noteworthy. It is possible that adolescents with a poor relationship with their parents were more likely to be physically abused [31] and have external beliefs and subsequently would be more likely to be depressed than others. As regards the controversy around association of birth order with child and adolescent depression, Gates et al. found that first born children scored significantly lower in the 27-item CDI than their siblings [32]. They found also that first born children showed higher levels of self-esteem than younger children. The results of the current study and the Gates et al. study do not give support to the Adlerian notion that a second born child is in a superior position to the first born child. However, Gates et al. explained that the first born child could be compensated for the pain of dethronement when the second child is born by the exclusive and generous attention received before the birth of this later born sibling [32].

\section{Study limitations}

This was a cross-sectional study, where temporal association of HLC and depres- 
sive symptoms could not be proved. It is impossible to tell whether those of low IHLC or high CHLC will develop depressive symptoms or that some variations in attitude might result from pre-existing health differences; for example, depressive symptoms lead to a fatalistic attitude. Therefore, longitudinal studies are required to prove the causal relationship and to test the association of HLC and depression rigorously.

The study findings cannot be generalized to the entire adolescent population in Alexandria as it was a school-based survey. Albeit education is universal in Alexandria, some adolescents drop classes or even leave school. However, it was not logistically feasible in this study to select a representative sample of adolescents from a household survey. Also, comparison between the study findings and other Arab studies is limited owing to the lack of previous studies investigating the association between HLC and adolescent depression.

Another study limitation to acknowledge is the internal consistency of the 2 subscales selected from the MHLC. Cronbach's alpha in the present study was $0.46-0.51$ which is lower than that in a study on an adult sample aged 40-79 years (0.62-0.76) [4], and in another study on hospitalized patients aged $18-65+$ years $(0.58-0.78)$ [24]. This could be explained by the difference in culture and in age group. However, to the best of the author's knowledge, this is the first large study to examine the MHLC in an adolescent community in Alexandria. Moreover, values above 0.4 may be considered adequate.

Finally, the depression scale used was not validated against a gold standard test such as the Revised Clinical Interview Schedule or the Composite International Diagnostic Interview. Indeed, for the cutoff score of 20, suggested as being suitable for screening in the general population (e.g. schools), clinicians will miss $86 \%$ of depressed children [33]. Nevertheless, there is no effect from different cultural norms as the scale has been used in countries such as Egypt and Oman in previous studies [12,31].

Although self-report questionnaires are easy to apply, they might also elicit inflated or false responses, especially for such sensitive subjects.

To conclude, the findings of this study give an indication of the extent of adolescent depression in Alexandria. They also indicate the predictors of adolescent depression and demonstrate the association between HLC and depression. Knowledge of the risk factors associated with adolescent depression would be of use in planning a programme for prevention and control. Moreover, exploring the association between adolescent depression and adolescent health beliefs could help in choosing or modifying health education programmes to promote adolescent mental health.

\section{References}

1. Jaffer YA, Afifi M. Adolescents' reproductive health and gender roles attitudes in Oman. Saudi medical journal, 2005, 26(2):234-40.

2. Jessor R. Risk behavior in adolescence: A psychological framework for understanding and action. Journal of adolescent health, 1991, 12:597-605.
3. Hashimoto $\mathrm{H}$, Fukuhara $\mathrm{S}$. The influence of locus of control on preferences for information and decision making. Patient education and counseling, 2004, 55(2):236-40.

4. Kuwahara A et al. Reliability and validity of the Multidimensional Health Locus of Control Scale in Japan: relationship with 
demographic factors and health-related behavior. Tohoku journal of experimental medicine, 2004, 203(1):37-45.

5. Wallston KA, Wallston BS. Development of the multidimensional health locus of control (MHLC) scales. Health education monographs, 1978, 6(2):160-70.

6. Mohit A. Mental health in the Eastern Mediterranean Region of the World Health Organization with a view of the future trends. Eastern Mediterranean health journal, 2001, 7(3):353-62.

7. Al-Sharbati MM, Al-Hussaini AA, Antony SX. Profile of child and adolescent psychiatry in Oman. Saudi medical journal, 2003, 24(4):391-5.

8. Afifi M. Mental health publications from the Arab world cited in PubMed, 1987-2002. Eastern Mediterranean health journal, 2005, 11(3):319-28.

9. Afifi M. Depression, aggression and suicide ideation among adolescents in Alexandria, Egypt. Neurosciences journal, 2004, 9(3):447-53.

10. Afifi M. Depression in adolescents: gender differences in Oman and Egypt. Eastern Mediterranean health journal, 2006, 12(1/2):61-71.

11. Christensen AJ et al. Health locus of control and depression in end-stage renal disease. Journal of consulting and clinical psychology, 1991, 59(3):419-24.

12. Afifi M. Adolescent use of health services in Alexandria, Egypt: association with mental health problems. Eastern Mediterranean health journal, 2003, 10(1/2):64-71.

13. Afifi M. Physical abuse and its association with aggressive and depressive symptomatology among adolescents in Alexandria. Paper presented at the 14th International Child Health Conference, 5-7 February 2001, Muscat, Oman.

14. Fahmy SI, El-Sherbini AF. Determining simple parameters for social classification for health research. Bulletin of the High Institute of Public Health, 1983, 8(5):95-9.

15. Kovacs M. Rating scales to assess depression in school-aged children. Acta paedopsychiatrica, 1981, 46(5-6):305-15.

16. Thomas $\mathrm{D}$ et al. Emerging practices in the prevention of child abuse and neglect. United States of America, Department of Health and Human Services, 2003:117 (http://nccanch.acf.hhs.gov/topics/prevention/emerging/report.pdf, accessed 22 April 2007).

17. Lachman ME, Weaver SL. The sense of control as a moderator of social class differences in health and well-being. Journal of personality and social psychology, 1998, 74(3):763-73.

18. Blaxter M. Whose fault is it? People's own conceptions of the reasons for health inequalities. Social science and medicine, 1997, 44(6):747-56.

19. Liu $X$ et al. Life events, locus of control, and behavioral problems among Chinese adolescents. Journal of clinical psychology, 2000, 56(12):1565-77.

20. Takakura M, Sakihara S. Psychosocial correlates of depressive symptoms among Japanese high school students. Journal of adolescent health, 2001, 28(1):82-9.

21. Dalgard OS, Lund Haheim L. Psychosocial risk factors and mortality: a prospective study with special focus on social support, social participation, and locus of control in Norway. Journal of epidemiology and community health, 1998, 52(8):476-81.

22. Wardle $\mathrm{J}$ et al. Depression, perceived control, and life satisfaction in university students from Central-Eastern and Western Europe. International journal of behavioral medicine, 2004, 11(1):27-36.

23. Soskolne $\mathrm{V}$ et al. Depressive symptoms in hospitalized patients: a cross-sectional 
survey. International journal of psychiatry in medicine, 1996, 26(3):271-85.

24. Voils $\mathrm{Cl}$ et al. Social support and locus of control as predictors of adherence to antidepressant medication in an elderly population. American journal of geriatric psychiatry, 2005, 13(2):157-65.

25. Fombonne $\mathrm{E}$ et al. The Maudsley longterm follow-up of child and adolescent depression. 1. Psychiatric outcomes in adulthood. British journal of psychiatry, 2001, 179:210-7.

26. McCauley Ohannessian $C$ et al. Does selfcompetence predict gender differences in adolescent depression and anxiety? Journal of adolescence, 1999, 22(3):397-411.

27. Glass RM. Blue mood, blackened lung. Journal of the American Medical Association, 1990, 264(12):1583-4.

28. Hughes JR et al. Prevalence of smoking among psychiatric out-patients. American journal of psychiatry, 1986, 143:993-7.
29. Louhiwuori KA, Hakama M. Risk of suicide among cancer patients. American journal of epidemiology, 1979, 109:59-60.

30. Roy A. Suicide in chronic schizophrenia. British journal of psychiatry, 1982, 141:171-7.

31. Afifi M. Study of school adolescent depression in the South Sharqiya region, Oman. Journal of the Bahrain Medical Society, 2000, 12(1):27-30.

32. Gates $L$ et al. Birth order and its relationship to depression, anxiety, and self-concept test scores in children. Journal of genetic psychology, 2001, 149(1):29-34.

33. Matthey S, Petrovski P. The Children's Depression Inventory: error in cut-off scores for screening purposes. Psychological assessment, 2000, 14(2):146-9. 